Research Paper

\title{
Relationship between Plasma Fibrinogen Levels and Pulmonary Function in the Japanese Population: The Takahata Study
}

Yoko Shibata $^{\bowtie}$, Shuichi Abe ${ }^{1}$, Sumito Inoue ${ }^{1}$, Akira Igarashi ${ }^{1}$, Keiko Yamauchi ${ }^{1}$, Yasuko Aida ${ }^{1}$, Hiroyuki Kishi $^{1}$, Keiko Nunomiya ${ }^{1}$, Hiroshi Nakano ${ }^{1}$, Masamichi Sato ${ }^{1}$, Kento Sato ${ }^{1}$, Tomomi Kimura ${ }^{1}$, Takako

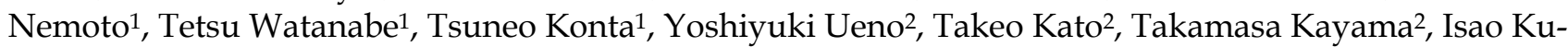
bota $^{1}$

1. Department of Cardiology, Pulmonology, and Nephrology;

2. Global Center of Excellence Program Study Group, Yamagata University School of Medicine, 2-2-2 Iida-Nishi, Yamagata 990-9585, Japan

$\triangle$ Corresponding author: Dr. Yoko Shibata, 2-2-2 Iida-Nishi, Yamagata City, Yamagata 990-9585, Japan. Telephone: +81-23-628-5302; Fax: +81-23-628-5305; Email: shibata@med.id.yamagata-u.ac.jp

(c) Ivyspring International Publisher. This is an open-access article distributed under the terms of the Creative Commons License (http://creativecommons.org/ licenses/by-nc-nd/3.0/). Reproduction is permitted for personal, noncommercial use, provided that the article is in whole, unmodified, and properly cited.

Received: 2013.07.25; Accepted: 2013.08.16; Published: 2013.09.01

\begin{abstract}
Background: Plasma fibrinogen is considered a biomarker of respiratory disease, owing to the relationship between plasma fibrinogen and pulmonary function established in Western populations. However, such a relationship has not yet been confirmed in an Asian population. We assessed this relationship in the general Japanese population.

Methods: Totally, 3,257 men and women aged $\geq 40$ years who participated in a community-based annual health checkup in Takahata, Japan, from 2004 to 2006, underwent spirometry, and their plasma fibrinogen levels were determined.

Results: We found an inverse relationship between spirometric measures (percent predicted forced vital capacity [\%FVC] and forced expiratory volume in Is [\%FEV 1 , and $F E V_{1} / F V C$ ) and plasma fibrinogen levels in men, but not in women. The plasma fibrinogen levels were significantly higher in subjects with restrictive, obstructive, and mixed ventilatory disorders than in those with normal spirometry results. Multiple linear regression analysis revealed that in men, plasma fibrinogen levels were predictive for \%FVC and \%FEV (independent of age, body mass index, and cigarette smoking) but not for $\mathrm{FEV} / \mathrm{FVC}$.
\end{abstract}

Conclusions: Plasma fibrinogen was significantly associated with pulmonary function in Japanese men, and as such, plasma fibrinogen might be a potent biomarker for pulmonary dysfunction in men.

Key words: Chronic Obstructive Pulmonary Disease; Decline in $\mathrm{FEV}_{1}$; Fibrinogen; Pulmonary function; Smoker; Spirometry

\section{Introduction}

Long-term exposure to cigarette smoke can induce many pulmonary diseases. Chronic obstructive pulmonary disease (COPD) is one of the most common respiratory disorders resulting from habitual smoking (1). COPD is a disorder characterized by chronic inflammation, not only in the respiratory system, but in the entire body, because inflammatory mediators are thought to spillover from the lung(s) into the rest of the body (2). The impact of COPD on the risk of mortality and chronic disability is serious, and preventative measures that can forestall the development of COPD are needed. 
Fibrinogen is an essential protein in the clotting cascade (3), and the plasma level of fibrinogen can be altered by various diseases. Furthermore, evidence suggesting that fibrinogen is a regulator of inflammation in disease is increasing (4) and circulating fibrinogen has, in recent studies, been identified as a potential biomarker for COPD (5). However, even though the plasma level of fibrinogen in patients with obstructive ventilatory disorder has been investigated, these levels have not yet been clearly determined in the patients with restrictive pulmonary disease such as pulmonary fibrosis. Intravascular coagulation is thought to be involved in the pathogenesis of idiopathic pulmonary fibrosis (6), and the results of experiments that use gene-targeted animal models suggest that fibrinogen is also involved in the pathogenesis of pulmonary fibrosis (7-9).

Thus far, only a few reports have shown a relationship between plasma fibrinogen levels and pulmonary function in a general population $(10,11)$. Kalhan et al. found that a high fibrinogen level in young adults was associated with a high risk of pulmonary function loss in their middle age (12).

To our knowledge, the relationship between plasma fibrinogen levels and pulmonary function in Asian individuals has not yet been studied. The aim of this study was to investigate the relationship between plasma fibrinogen levels and pulmonary function in the general Japanese population.

\section{Methods}

\section{Study population}

This study was part of the Molecular Epidemiological Study of the Regional Characteristics of 21st Century Centers of Excellence (COE) Program and the Global Centers of Excellence Program in Japan (13-19). The Ethics Committee of Yamagata University School of Medicine approved the study, the study was conducted in accordance with the Declaration of Helsinki and all the participants gave written informed consent prior to enrollment.

Data were collected during an annual community health checkup, for which, all residents aged $\geq 40$ years in Takahata town in northern Japan were invited. From 2004 through 2006, 3,520 men $(n=1,579)$ and women $(\mathrm{n}=1,941)$ were enrolled in the study, and all of them underwent spirometry. We excluded the data of 263 subjects because their spirometry results did not meet the study's specified criteria. Finally, our final sample set comprised the data of 3,257 subjects (1,502 men; 1,755 women) for statistical analysis. Subjects used a self-report questionnaire to document their medical histories, smoking habits, current use of medications, and clinical symptoms.
The lifetime consumption of cigarettes was expressed as the Brinkman index (BI; number of cigarettes per day $\times$ years of smoking) $(16,17)$.

\section{Measurements}

Blood samples were taken from the antecubital vein of subjects who had been overnight-fasting, and the samples were immediately transferred to chilled tubes. Plasma fibrinogen was measured according to the clotting method. Study subjects were grouped in quartiles based on fibrinogen measurements.

Forced vital capacity (FVC) and forced expiratory volume in $1 \mathrm{~s}\left(\mathrm{FEV}_{1}\right)$ were measured using standard techniques, with subjects performing FVC maneuvers on a CHESTAC-25 part II EX instrument (Chest Corp., Tokyo, Japan), according to the guidelines of the Japanese Respiratory Society (JRS) (20). Data were expressed as a percentage of predicted values or as a ratio $\left(\% \mathrm{FVC}, \% \mathrm{FEV}_{1}\right.$ and $\left.\mathrm{FEV}_{1} / \mathrm{FVC}\right)$ (17). Administration of bronchodilators was not allowed prior to spirometry. For each subject, the highest value from at least 3 FVC maneuvers was used in our analysis. The results were assessed by 2 pulmonary physicians, who visually inspected the flow-volume curves and excluded subjects with inadequate data, as defined by the JRS criteria (20). Subjects' pulmonary functions were classified as follows: normal, $\% \mathrm{FVC} \geq 80 \%$ and $\mathrm{FEV}_{1} / \mathrm{FVC} \geq 0.7$; restrictive, $\% \mathrm{FVC}<80 \%$ and $\mathrm{FEV}_{1} / \mathrm{FVC} \geq 0.7$; obstructive, $\% \mathrm{FVC} \geq 80 \%$ and $\mathrm{FEV}_{1} / \mathrm{FVC}<0.7$; and mixed disorder, $\% \mathrm{FVC}<80 \%$ and $\mathrm{FEV}_{1} / \mathrm{FVC}<0.7$.

\section{Statistical analyses}

For continuous variables, data are presented as mean (SD). For multiple comparisons, one-way analysis of variance was used, followed by the Tukey's test. Correlations between 2 variables were evaluated using Pearson's product moment correlation coefficient. Multiple linear regression analysis was performed to determine whether plasma fibrinogen levels were associated with spirometric measures after adjustment for all other variables included in the model. Statistical significance was considered for two-sided $P$ values $<0.05$. All statistical analyses were performed using JMP version 8 software (SAS Institute Inc., Cary, NC, USA).

\section{Results}

Mean (SD) of the plasma fibrinogen level was 334.2 (70.8) $\mathrm{mg} / \mathrm{dL}$. There were no significant difference in the fibrinogen levels between men and women (men, 335.8 [76.1] mg/dL; women, 332.8 [66.1] $\mathrm{mg} / \mathrm{dL} ; \mathrm{P}=0.217)$.

Median (inter-quartile range) of the plasma fibrinogen level was $325 \mathrm{mg} / \mathrm{dL}(283-378 \mathrm{mg} / \mathrm{dL})$ in 
men and $320 \mathrm{mg} / \mathrm{dL}$ (range, 287-371 mg/dL) in women. Table 1 shows the characteristics of subjects according to quartiles of fibrinogen. In both men and women, the mean age increased in accordance with the quartile increase in fibrinogen. The mean body mass index (BMI) of men decreased in the highest quartile, while the mean BMI of women increased in accordance with the quartile increase in fibrinogen. Compared with the lowest quartile, the BI of men increased in the highest quartile in men. Percentages of current smoker were not significantly different among these quartiles both men and women. Because the smoking rate in the Japanese population in 2005 was approximately $39.3 \%$ among males and $11.3 \%$ among females, the smoking rate in this study population seems to be lower than those of Japanese general population (21). In men, the \%FVC did not differ between the fibrinogen quartile ranges, but the $\% \mathrm{FEV}_{1}$ and $\mathrm{FEV}_{1} / \mathrm{FVC}$ decreased in accordance with an increase in fibrinogen quartiles. In women, the \%FVC and $\% \mathrm{FEV}_{1}$ decreased in the highest quartile when compared with the values recorded for the third quartile, while the $\mathrm{FEV}_{1} / \mathrm{FVC}$ did not differ among fibrinogen quartiles.

Figure 1 shows the relationship between plasma fibrinogen levels and spirometric measurements in men (Fig. 1A, C, and E) and women (Fig. 1B, D, and $\mathrm{F})$. There were significant inverse relationships between plasma fibrinogen levels and spirometric measurements in men, but not in women. Table 2 shows the mean plasma fibrinogen levels according to spirometric classifications of normal, restrictive, obstructive, and mixed ventilatory disorders. The plasma level of fibrinogen was significantly higher in men with restrictive, obstructive, and mixed disorders than in those with normal spirometry values (Table 2A). The fibrinogen levels in women differed significantly between groups, but a post hoc analysis did not reveal any significant differences in pair-wise comparisons (Table 2B). Percentages of subjects whose baseline fibrinogen level was over cut-off point (fibrinogen $\geq$ 350) were also examined in each spirometric classification. In men, percentages of those subjects in restrictive, obstructive and mixed pulmonary disorder patterns were significantly higher than those in normal spirometry, but not in women (Table 2A and B).

Plasma fibrinogen levels were significantly associated with age and BMI in both men and women and with BI in men (Table 1). We investigated whether the associations between plasma fibrinogen and spirometric measurements were independent of age, BMI, and BI. In men, the plasma fibrinogen level was a significant determinant of $\% \mathrm{FVC}$ and $\% \mathrm{FEV}_{1}$, but it was not predictive for $\mathrm{FEV}_{1} / \mathrm{FVC}$ (Table $3 \mathrm{~A}$ ). In women, the plasma fibrinogen level was not an independent predictor for spirometric measurements (Table 3B).

Table I. Characteristics of the subjects according to the quartile range of fibrinogen.

\begin{tabular}{|c|c|c|c|c|c|}
\hline \multicolumn{6}{|l|}{ A. Men } \\
\hline & $\begin{array}{l}Q 1 \\
(n=373)\end{array}$ & $\begin{array}{l}\mathrm{Q} 2 \\
(\mathrm{n}=369)\end{array}$ & $\begin{array}{l}\text { Q3 } \\
(\mathrm{n}=375)\end{array}$ & $\begin{array}{l}\mathrm{Q4} \\
(\mathrm{n}=380)\end{array}$ & $\mathbf{P}$ \\
\hline Age, year & $58.9(10.6)$ & $61.7(10.1)^{*}$ & $64.7(10.0)^{* \#}$ & $65.9(9.6)^{\star \#}$ & $<0.0001$ \\
\hline BMI, $\mathrm{kg} / \mathrm{m}^{2}$ & $23.6(2.8)$ & $23.7(3.0)$ & $23.7(2.9)$ & 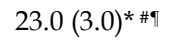 & 0.0007 \\
\hline BI, cigarette $\times$ year & $370.5(480.5)$ & 446.9 (497.9) & $425.6(451.0)$ & $524.2(539.6)^{*}$ & 0.0014 \\
\hline Current smoker,\% & 31.1 & 33.2 & 36.0 & 38.8 & 0.134 \\
\hline$\% \mathrm{FVC}$ & $98.4(13.4)$ & $98.1(14.5)$ & $96.9(15.6)$ & 95.7 (15.6) & 0.0588 \\
\hline$\% \mathrm{FEV}_{1}$ & 97.7 (15.6) & $96.7(16.1)$ & $95.1(18.5)$ & $92.6(18.9)$ *\# & 0.0003 \\
\hline $\mathrm{FEV}_{1} / \mathrm{FVC}, \%$ & $78.2(7.6)$ & $77.6(7.9)$ & $76.7(9.6)$ & $75.4(9.9)^{* \#}$ & 0.0001 \\
\hline \multicolumn{6}{|l|}{ B. Women } \\
\hline & $\begin{array}{l}\mathrm{Q} 1 \\
(\mathrm{n}=423)\end{array}$ & $\begin{array}{l}\mathrm{Q} 2 \\
(\mathrm{n}=386)\end{array}$ & $\begin{array}{l}\text { Q3 } \\
(\mathrm{n}=496)\end{array}$ & $\begin{array}{l}\mathrm{Q4} \\
(\mathrm{n}=437)\end{array}$ & $\mathbf{P}$ \\
\hline Age, year & $57.3(10.7)$ & $60.8(10.0)^{*}$ & $63.8(9.5)^{* \#}$ & $64.4(9.4)^{* \#}$ & $<0.0001$ \\
\hline BMI, $\mathrm{kg} / \mathrm{m}^{2}$ & $22.9(3.3)$ & $23.4(3.3)$ & $23.7(3.3)^{*}$ & $23.9(3.5)^{* \#}$ & $<0.0001$ \\
\hline BI, cigarette $\times$ year & $20.6(88.8)$ & $15.0(83.7)$ & $15.8(77.5)$ & $18.2(108.0)$ & 0.8195 \\
\hline Current smoker, $\%$ & 7.8 & 4.4 & 5.4 & 5.1 & 0.165 \\
\hline$\% \mathrm{FVC}$ & 99.7 (13.2) & $100.1(13.4)$ & $101.1(15.2)$ & $98.3(14.9)^{\uparrow}$ & 0.0285 \\
\hline$\% \mathrm{FEV}_{1}$ & $99.3(14.3)$ & $99.8(14.5)$ & 101.2 (15.7) & $98.3(16.8)^{\uparrow}$ & 0.0413 \\
\hline $\mathrm{FEV}_{1} / \mathrm{FVC}, \%$ & $80.2(6.1)$ & $80.0(6.5)$ & $79.9(6.2)$ & $79.8(7.2)$ & 0.7331 \\
\hline
\end{tabular}

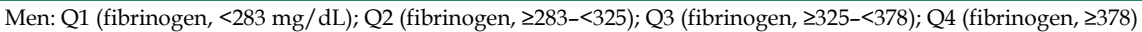

Women: Q1 (fibrinogen, <287); Q2 (fibrinogen, $\geq 287-<320) ; \mathrm{Q} 3$ (fibrinogen, $\geq 320-<371$ ); Q4 (fibrinogen, $\geq 371$ )

*: $\mathrm{P}<0.05$ vs $\mathrm{Q} 1$, \#: $\mathrm{P}<0.05$ vs $\mathrm{Q} 2$, r: $\mathrm{P}<0.05$ vs $\mathrm{Q} 3$

Values are means (SD) or percentage. Differences among each quartile were evaluated by one-way analysis of variance followed by Tukey's method or chi-square test. $\mathrm{BMI}$, body mass index; $\mathrm{BI}$, Brinkman index; FVC, forced vital capacity; $\mathrm{FEV}_{1}$, forced expiratory volume in $1 \mathrm{~s}$ 

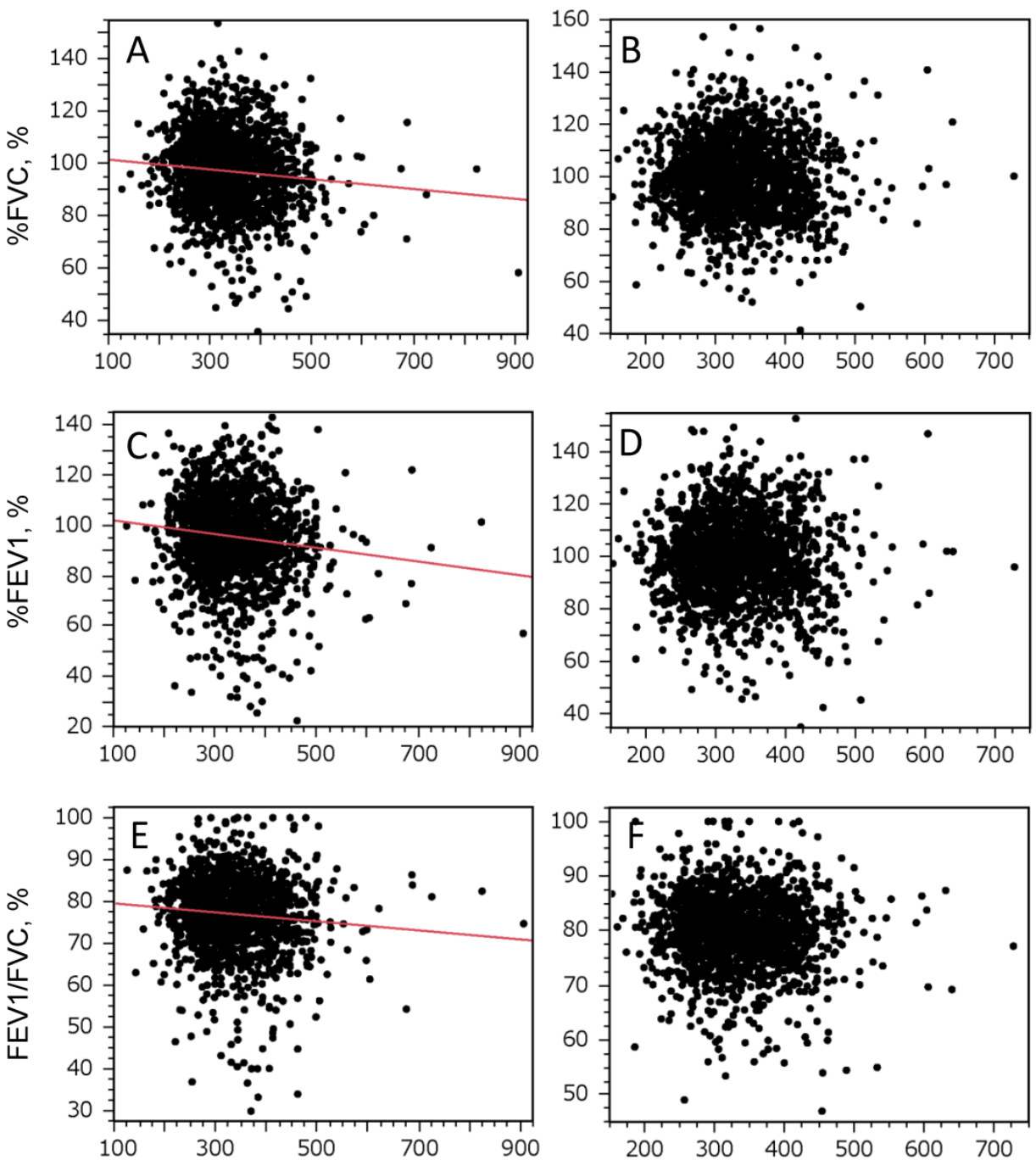

Fibrinogen level $(\mathrm{mg} / \mathrm{dL})$

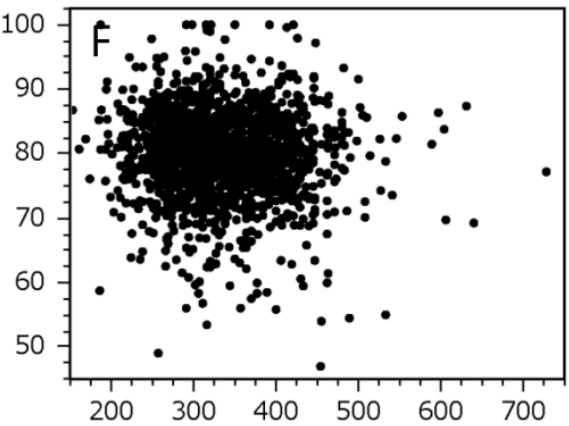

Fibrinogen level (mg/dL)

Fig. I. Correlation between the plasma fibrinogen levels and the predicted percentage forced vital capacity (\%FVC), predicted percentage forced expiratory volume in Is $\left(\% F E V_{1}\right)$, and the FEV $/$ FVC. The plasma fibrinogen levels of men are inversely correlated with the predicted percentage forced vital capacity (\%FVC), predicted percentage forced expiratory volume in Is (\%FEV $)_{1}$ ), and $\mathrm{FEV}_{1} / \mathrm{FVC}$. The graphs show the relationships between spirometric measures and plasma levels of fibrinogen in men $(A, C$, and $E)$ and women $(B, D$, and $F)$. Correlations were evaluated using Pearson's product moment correlation coefficient. A statistically significant relationship was observed only in men $(A, r=-0.10, P=0.002 ; C, r=$ $-0.12, P<0.0001 ; \mathrm{E}, r=-0.09, P=0.0004)$.

Table 2. Mean fibrinogen concentration relative to the type of spirometric disorder

\begin{tabular}{|c|c|c|c|c|c|}
\hline \multicolumn{6}{|l|}{ A. Men } \\
\hline & $\begin{array}{l}\text { Normal } \\
(\mathrm{n}=1162)\end{array}$ & $\begin{array}{l}\text { Restrictive } \\
(\mathrm{n}=96)\end{array}$ & $\begin{array}{l}\text { Obstructive } \\
(\mathrm{n}=184)\end{array}$ & $\begin{array}{l}\text { Mixed } \\
(\mathrm{n}=55)\end{array}$ & $\mathbf{P}$ \\
\hline Fibrinogen (mg/dL) & $330.9(72.9)$ & $356.4(97.0)^{*}$ & $348.5(76.3)^{*}$ & $360.2(83.2)^{*}$ & $<0.0001$ \\
\hline Fibrinogen $\geq 350, \%$ & 36.4 & 45.3 & 50.0 & 47.3 & 0.001 \\
\hline \multicolumn{6}{|l|}{ B. Women } \\
\hline & $\begin{array}{l}\text { Normal } \\
(\mathrm{n}=1545)\end{array}$ & $\begin{array}{l}\text { Restrictive } \\
(\mathrm{n}=99)\end{array}$ & $\begin{array}{l}\text { Obstructive } \\
(\mathrm{n}=80)\end{array}$ & $\begin{array}{l}\text { Mixed } \\
(\mathrm{n}=18)\end{array}$ & $\mathbf{P}$ \\
\hline Fibrinogen (mg/dL) & $330.2(64.7)$ & $343.4(68.3)$ & $347.0(81.4)$ & $365.2(61.8)$ & 0.005 \\
\hline Fibrinogen $\geq 350, \%$ & 36.4 & 41.4 & 46.3 & 50.0 & 0.155 \\
\hline
\end{tabular}

Fibrinogen concentrations were not available in 383 men and 387 women.

Values are presented as mean (SD) or percentage. Differences among each group were evaluated by one-way analysis of variance followed by Tukey's method or chi-square test.

*: $\mathrm{P}<0.05$ vs normal group 
Table 3. Multiple linear regression analysis of the relationship between plasma fibrinogen and the predicted percentage forced vital capacity (\%FVC), predicted percentage forced expiratory flow in I s (\%FEV $)$, and FEV $/ F V C$

\begin{tabular}{|c|c|c|c|}
\hline \multicolumn{4}{|l|}{ A. Men } \\
\hline & Coefficient & SD & $\mathbf{P}$ \\
\hline$\% \mathrm{FVC}$ & -0.016 & 0.006 & 0.005 \\
\hline$\% \mathrm{FEV}_{1}$ & -0.018 & 0.006 & 0.007 \\
\hline $\mathrm{FEV}_{1} / \mathrm{FVC}$ & -0.001 & 0.003 & 0.757 \\
\hline \multicolumn{4}{|l|}{ B. Women } \\
\hline & Coefficient & SD & $\mathbf{P}$ \\
\hline$\% \mathrm{FVC}$ & -0.007 & 0.005 & 0.229 \\
\hline$\%$ FEV1 & -0.007 & 0.006 & 0.213 \\
\hline FEV1/FVC & -0.0002 & 0.002 & 0.916 \\
\hline \multicolumn{4}{|c|}{ C. Men (except for those with a pure restrictive spirometric pattern) } \\
\hline & Coefficient & SD & $\mathbf{P}$ \\
\hline$\%$ FEV1 & -0.018 & 0.007 & 0.007 \\
\hline
\end{tabular}

Fibrinogen values were adjusted for age, body mass index, and Brinkman index.

$\mathrm{SD}$, standard deviation

In restrictive ventilatory disorders, $\% \mathrm{FEV}_{1}$ is known to be decreased, and in an effort to avoid any potential effects of lung restriction on $\% \mathrm{FEV}_{1}$, we performed a multiple linear regression analysis in which the data from male subjects with pure restrictive disorder were excluded. In that analysis, fibrinogen was still predictive for $\% \mathrm{FEV}_{1}$ (Table $3 \mathrm{C}$ ).

\section{Discussion}

The present study identified an inverse relationship between spirometric measurements (\%FVC, $\% \mathrm{FEV}_{1}$, and $\mathrm{FEV}_{1} / \mathrm{FVC}$ ) and plasma fibrinogen levels in Japanese men who participated in an annual health checkup. The plasma fibrinogen levels were significantly higher in the subjects with restrictive, obstructive, and mixed ventilatory disorders than in those with normal spirometry values. Multiple linear regression analysis revealed that in men, plasma fibrinogen levels were predictive for $\% \mathrm{FVC}$ and $\% \mathrm{FEV}_{1}$ and independent of age, BMI, and $\mathrm{BI}$, but not predictive for $\mathrm{FEV}_{1} / \mathrm{FVC}$.

Plasma fibrinogen levels are gaining recognition as a biomarker for COPD (5). Dahl et al. demonstrated an inverse relationship between plasma fibrinogen levels and $\% \mathrm{FEV}_{1}$ in a Danish general population; they also showed that higher fibrinogen levels could be associated with a faster decline in lung function (10). In 2 general populations in the United States, higher baseline levels of fibrinogen were associated with a higher incidence of COPD, COPD-related hospitalization, and all-cause mortality (11). In the Third National Health and Nutrition Examination, plasma levels of fibrinogen were higher in COPD patients, and these levels were associated with a degree of airflow limitation, which is one of the parameters used to assess the severity of COPD (22). Although plasma fibrinogen levels were not associated with the annual decline in $\mathrm{FEV}_{1}$ in COPD patients (23), a meta-analysis found that the plasma fibrinogen level was associated with death from COPD (24). In addition, elevated levels of inflammatory biomarkers, including plasma fibrinogen, were associated with a risk of major comorbidities in COPD, including cardiovascular diseases, type II diabetes, lung cancer, and pneumonia (25). Evidence for a role of plasma fibrinogen in patients with COPD and in the general population in Western countries is increasing. Therefore, it is thought that measuring plasma fibrinogen levels in cigarette smokers and patients with COPD is important, because it could indicate disease severity and comorbidities and assist in predicting the disease prognosis.

Although there is evidence for a relationship between plasma fibrinogen levels and pulmonary function in Western populations, a similar relationship has not yet been demonstrated in an Asian population. The results of this study show that the plasma fibrinogen level is associated with pulmonary function in Japanese men and that the plasma fibrinogen level could thus be a potent biomarker of COPD in Japanese men. This biomarker is particularly useful because it is easy and relatively cheap to use for measurement of plasma fibrinogen levels.

It is important to note that we did not identify a relationship between the plasma fibrinogen level and pulmonary function in Japanese women. The smoking rate among Japanese women is relatively low, and the prevalence of COPD amongst Japanese women is therefore lower than that in Japanese men (17). The absence of an association between the plasma fibrinogen level and pulmonary function in Japanese 
women may well be related to the low prevalence of COPD among our female subjects.

Unlike previous reports (10), we could not show that baseline plasma fibrinogen levels are predictive of an annual decline in pulmonary functions in men (data not shown). We do not know the precise reason for this difference, and we speculate that it could be related to ethical differences or a lack of statistical power related to the number of male subjects in the second spirometry follow-up of the study $(\mathrm{n}=147)$ (16). Further studies may be required to ascertain whether plasma fibrinogen levels could be predictive of pulmonary function decline in Japanese individuals.

Fibrinogen is an acute phase protein in plasma, which converts thrombin into fibrin in the blood coagulation cascade (26). A study that investigated single nucleotide polymorphisms (SNPs) of the fibrinogen beta chain-coding gene failed to demonstrate an association between SNPs or related phenotypes and the risk of COPD (27). In addition, a genome-wide study with COPD patients reported that SNPs of fibrinogen-related genes are not associated with the development of COPD (28-34). Therefore, elevated levels of fibrinogen in the subjects with impaired pulmonary function are likely a reflection of disease status rather than a causal factor. It is known that plasma levels of fibrinogen are elevated in inflammatory diseases $(35,36)$, and COPD is well recognized as a disease of systemic, chronic, and low-grade inflammation because inflammatory mediators spill over from the lungs into circulation (2). Therefore, many of our study subjects with airflow limitations may well have had systemic, chronic, and low-grade inflammation. This inflammatory response likely resulted from the activation of the same inflammatory pathways that are activated in COPD and the direct toxic effect of cigarette smoking. This, in turn, could explain the elevation of plasma fibrinogen levels in our male subjects. The plasma fibrinogen levels in patients with exacerbated COPD were significantly higher than in those with stable COPD, and plasma fibrinogen levels could thus serve as a useful biomarker for the evaluation of exacerbated COPD (37).

In our study, the plasma fibrinogen level was significantly associated with the \%FVC in Japanese men. The $\% \mathrm{FVC}$ is a parameter for lung restriction, and fibrosing lung diseases (FLDs) are characterized by restrictive ventilatory disease. The prevalence of FLDs is low (38), and, to our knowledge, the relationship between FLD and plasma fibrinogen levels has not yet been reported, although some reports suggested that fibrinogen could have a significant role in the pathogenesis of FLD (6-9). Not all subjects with restrictive ventilatory disorders in our study were thought to have FLDs. Nevertheless, our results suggest a significant role for fibrinogen in the restrictive ventilatory disorders.

The present study had several limitations, mainly because it was not a hospital-based study. Further, the lack of information regarding chest radiography findings, the final diagnosis, and consumed medication, which could have affected fibrinogen levels, might be potential limitations. Additionally, there is a possibility of sampling bias, because subjects could have participated in the present study because of their socioeconomic circumstances.

In conclusion, we found that the plasma fibrinogen level of Japanese men, but not women, is associated with the pulmonary functions $\% \mathrm{FEV}_{1}$ and \%FVC. Our findings suggest that plasma fibrinogen may be a potent biomarker for pulmonary dysfunction in Japanese men.

\section{Acknowledgments}

We thank Taiko Aita, Emiko Nakamura, and Eiji Tsuchida for their excellent technical assistance. We also thank the additional contributors: Michiko Nishiwaki (Saiseikan Yamagata City Hospital, Yamagata Japan), Toshihiro Wada (Saiseikan Yamagata City Hospital, Yamagata Japan), Jun-Ichi Machiya (Nihonkai General Hospital, Sakata Japan), Noriyuki Hirama (NHO Yamagata National Hospital, Yamagata Japan), Noriaki Takabatake (Tohoku Central Hospital, Yamagata Japan), Makoto Sata (National Cerebral and Cardiovascular Center, Osaka Japan)

\section{Funding}

This study was supported by a grant-in-aid from the Global COE Program of the Japan Society for the Promotion of Science, and grants-in-aid for Scientific Research from the Ministry of Education, Culture, Sports, Science and Technology, Japan (19590880, 20590892, and 23390220).

\section{Ethics committee approval}

This study was approved by the institutional ethics committee and all participants gave written informed consent.

\section{Competing Interests}

The authors have declared that no competing interest exists.

\section{References}

1 [Internet] Global initiative for chronic obstructive lung disease. Global strategy for the diagnosis, management and prevention of chronic obstructive pulmonary disease. http://www.goldcopd.org/

2 Barnes PJ. Celli BR Systemic manifestations and comorbidities of COPD. Eur Respir J. 2009; 33: 1165-85.

3 Lord ST. Molecular mechanisms affecting fibrin structure and stability. Arterioscler Thromb Vasc Biol. 2011; 31: 494-9. 
4 Davalos D, Akassoglou K. Fibrinogen as a key regulator of inflammation in disease. Semin Immunopathol. 2012; 34: 43-62.

5 Duvoix A, Dickens J, Haq I, et al. Blood fibrinogen as a biomarker of chronic obstructive pulmonary disease. Thorax. 2012.

6 Kubo H, Nakayama K, Yanai M, et al. Anticoagulant therapy for idiopathic pulmonary fibrosis. Chest. 2005; 128: 1475-82.

7 Hattori N, Degen JL, Sisson TH, et al. Bleomycin-induced pulmonary fibrosis in fibrinogen-null mice. J Clin Invest. 2000; 106: 1341-50.

8 Ploplis VA, Wilberding J, McLennan L, et al. A total fibrinogen deficiency is compatible with the development of pulmonary fibrosis in mice. Am J Pathol. 2000; 157: 703-8.

9 Wilberding JA, Ploplis VA, McLennan L, et al. Development of pulmonary fibrosis in fibrinogen-deficient mice. Ann N Y Acad Sci. 2001; 936: 542-8.

10 Dahl M, Tybjaerg-Hansen A, Vestbo J, et al. Elevated plasma fibrinogen associated with reduced pulmonary function and increased risk of chronic obstructive pulmonary disease. Am J Respir Crit Care Med. 2001; 164: 1008-11.

11 Valvi D, Mannino DM, Mullerova H, et al. Fibrinogen, chronic obstructive pulmonary disease (COPD) and outcomes in two united states cohorts. Int J Chron Obstruct Pulmon Dis. 2012; 7: 173-82.

12 Kalhan R, Tran BT, Colangelo LA, et al. Systemic inflammation in young adults is associated with abnormal lung function in middle age. PLoS One. 2010; 5: e11431.

13 Aida Y, Shibata Y, Osaka D, et al. The relationship between serum uric acid and spirometric values in participants in a health check: The Takahata study. Int J Med Sci. 2011; 8: 470-8.

14 Kishi H, Shibata Y, Osaka D, et al. FEV 6 and $\mathrm{FEV}_{1} / \mathrm{FEV}_{6}$ in Japanese participants of the community-based annual health check: The Takahata study. Intern Med. 2011; 50: 87-93.

15 Nemoto T, Shibata Y, Osaka D, et al. Impact of cigarette smoking on maximal expiratory flows in a general population: The Takahata study. Intern Med. 2011; 50: 2547-55.

16 Nunomiya K, Shibata Y, Abe S, et al. Hyperhomocysteinaemia predicts the decline in pulmonary function in healthy male smokers. Eur Respir J. 2013; 42: 18-27.

17 Osaka D, Shibata Y, Abe S, et al. Relationship between habit of cigarette smoking and airflow limitation in healthy Japanese individuals: The Takahata study. Intern Med. 2010; 49: 1489-99.

18 Sato M, Shibata Y, Abe S, et al. Retrospective analysis of the relationship between decline in $\mathrm{FEV}_{1}$ and abdominal circumference in male smokers: The Takahata study. Int J Med Sci. 2013; 10: 1-7.

19 Shibata Y, Watanabe T, Osaka D, et al. Impairment of pulmonary function is an independent risk factor for atrial fibrillation: The Takahata study. Int J Med Sci. 2011; 8: 514-22.

20 The Committee of Pulmonary Physiology Japanese Respiratory Society. Guidelines for pulmonary function tests: Spirometry, flow-volume curve, diffusion capacity of the lung. Tokyo: The Committee of Pulmonary Physiology Japanese Respiratory Society, 2004.

21 [Internet] Ministry of Health Labour and Welfare. Measures for national health promotion. http://www.mhlw.go.jp/english/wp/wp-hw2/ part2/p3_0024.pdf.

22 Mannino DM, Ford ES, Redd SC Obstructive and restrictive lung disease and markers of inflammation: Data from the Third National Health and Nutrition Examination. Am J Med. 2003; 114: 758-62.

23 Vestbo J, Edwards LD, Scanlon PD, et al. Changes in forced expiratory volume in 1 second over time in COPD. N Engl J Med. 2011; 365: 1184-92.

24 Danesh J, Lewington S, Thompson SG, et al. Plasma fibrinogen level and the risk of major cardiovascular diseases and nonvascular mortality: An individual participant meta-analysis. JAMA. 2005; 294: 1799-809.

25 Thomsen $\mathrm{M}$, Dahl M, Lange $\mathrm{P}$, et al. Inflammatory biomarkers and comorbidities in chronic obstructive pulmonary disease. Am J Respir Crit Care Med. 2012; 186: 982-8.

26 Wolberg AS. Determinants of fibrin formation, structure, and function. Curr Opin Hematol. 2012; 19: 349-56.

27 Yanbaeva DG, Dentener MA, Spruit MA, et al. IL6 and CRP haplotypes are associated with COPD risk and systemic inflammation: A case-control study. BMC Med Genet. 2009; 10: 23.

28 Brehm JM, Hagiwara K, Tesfaigzi Y, et al. Identification of FGF7 as a novel susceptibility locus for chronic obstructive pulmonary disease. Thorax. 2011; 66: 1085-90.

29 Cho MH, Castaldi PJ, Wan ES, et al. A genome-wide association study of COPD identifies a susceptibility locus on chromosome 19q13. Hum Mol Genet. 2012; 21: 947-57.

30 Guo Y, Lin H, Gao K, et al. Genetic analysis of IREB2, FAM13A and XRCC5 variants in Chinese Han patients with chronic obstructive pulmonary disease. Biochem Biophys Res Commun. 2011; 415: 284-7.
31 Kong X, Cho MH, Anderson W, et al. Genome-wide association study identifies BICD1 as a susceptibility gene for emphysema. Am J Respir Crit Care Med. 2011; 183: 43-9.

32 Pillai SG, Ge D, Zhu G, et al. A genome-wide association study in chronic obstructive pulmonary disease (COPD): Identification of two major susceptibility loci. PLoS Genet. 2009; 5: e1000421.

33 Repapi E, Sayers I, Wain LV, et al. Genome-wide association study identifies five loci associated with lung function. Nat Genet. 2010; 42: 36-44.

34 Wilk JB, Shrine NR, Loehr LR, et al. Genome-wide association studies identify CHRNA5/3 and HTR4 in the development of airflow obstruction. Am J Respir Crit Care Med. 2012; 186: 622-32.

35 Danik JS, Pare G, Chasman DI, et al. Novel loci, including those related to crohn disease, psoriasis, and inflammation, identified in a genome-wide association study of fibrinogen in 17686 women: The women's genome health study. Circ Cardiovasc Genet. 2009; 2: 134-41.

36 Lind L. Circulating markers of inflammation and atherosclerosis. Atherosclerosis. 2003; 169: 203-14.

37 Polatli M, Cakir A, Cildag O, et al. Microalbuminuria, von willebrand factor and fibrinogen levels as markers of the severity in COPD exacerbation. J Thromb Thrombolysis. 2008; 26: 97-102.

38 Munakata M, Asakawa M, Hamma Y, et al. [Present status of idiopathic interstitial pneumonia--from epidemiology to etiology]. Nihon Kyobu Shikkan Gakkai Zasshi. 1994; 32 Suppl: 187-92. 